\title{
LABOR RESOURCES OF REPUBLIC OF TATARSTAN AND THEIR SPATIAL DIFFERENCES
}

\author{
Gabdrakhmanov N.K. \\ Kazan Federal University,
} Institute of Management, Economics and Finance, Kazan, 420008, Russia

\author{
Safiullin L.N. \\ Kazan Federal University, \\ Institute of Management, Economics and Finance, \\ Kazan, 420008, Russia \\ Center of Advanced Economic Research Academy of \\ Sciences of the Republic of Tatarstan, \\ Kazan, 420008, Russia
}

\author{
Ulesov D.V. \\ Kazan Federal University, \\ Institute of Management, Economics and Finance, \\ Kazan, 420008, Russia
}

Islamutdinova D.F.

Yugra State University, Khanty-Mansiysk, 628011, Russia

\author{
Maratkanova E.M. \\ Kazan Federal University, \\ Kazan, 420008, Russia
}

\begin{abstract}
The process of effective decision-making in the framework of integrated regional development programs is based on the rational use of resources. However, in the situation of international competition, socio-economic development of the region becomes less dependent on the amount of natural resources. The most important resource within the geographical territory is the population living on it - a number of people which is put together in the process of social production and consumption. Labor potential is formed under the influence of the whole complex of social and economic factors.
\end{abstract}

The main factors reflecting the status of workforce potential used in the present study were: labour force share in the proportion of the total population; the proportion of actively working population; the proportion of employed in the total labor force; the proportion of employed in the total workforce in the key sectors; the rate of unemployment.

The analysis of labor force potential of the Republic of Tatarstan resulted in possibility to divide all administrative regions into 5 groups. These are the regions characterized by a high level of labor force potential; regions with an above average level of labor force potential; regions which are said to have an average level of labor force potential; regions with a below average level of labor force potential; regions characterized by a low level of labor force potential [6].
Keywords - population, spatial heterogeneity, labor force, workforce potential, integrated assessment of labor force.

\section{INTRODUCTION}

The Republic of Tatarstan is one of the most economically developed regions in Russia [11]. Competitive advantages of Tatarstan are: favorable geographical position at the crossroads of major highways connecting north and south, west and east of the country; rich natural resources; developed transport infrastructure and a powerful industrial sector.

The process of effective decision-making in the framework of integrated regional development programs is better based on the rational use of resources [6]. However, in the face of international competition, social and economic development the area is becoming less dependent on natural resources. The most important resource within the geographical territory of a population living on it is the amount of people united in the process of social production and consumption [9].

The change in the amount of populationis one of the objective factors, reflecting the competitiveness of the region. Thus, the inflow of population to the region increases the demand and supply of goods, the formation of the tax base, economic growth and development of the region as a whole. Otherwise, the outflow of population from the concrete territory indicates either bad living conditions or low quality of life [8]. 
In January, 2014, the population of the Republic of Tatarstan amounted to 3838.2 people. Figure 1 shows the number of the permanent population of the Republic of Tatarstan for 1996-2015.

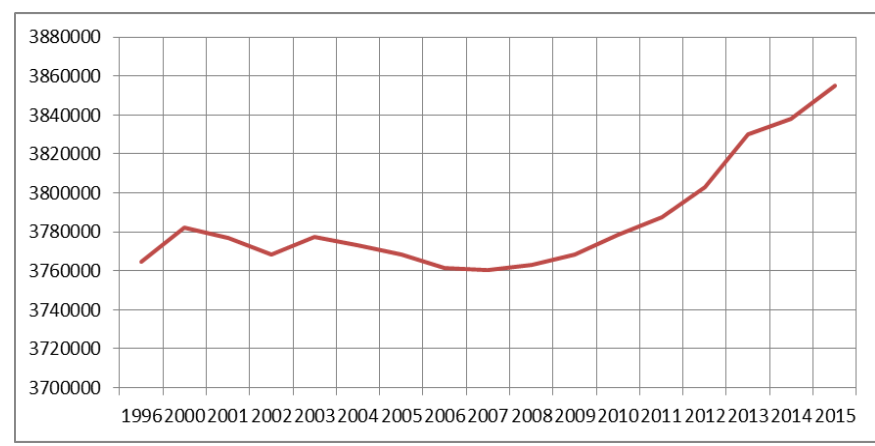

Fig. 1. The dynamics of the resident population of the Republic of Tatarstan for 1996-2015.

The tendency of population dynamics is better illustrated by the linear equation represented below. During the research period the resident population of the republic changed annually by 2492.4 people. In socio-economic terms, the population - is interconnected with the economy and social sphere and builds the main production force of the society that is human resources of the area. Human resources are a part of the working population of the country engaged in a social production including those people who are supposed to be employed. Thus, human resources constitute the fundamental basis of production [10,11]. Lange scale projects implemented in the Republic of Tatarstan have high demands to the labor provision. In this regard, the study of labor potential and its links to the age and sex structures of population is of great importance.

The relevance of the research of this kind is determined by theoretical and practical significance of the problem of reproduction and the optimal use of human resources for the rapidly developing region of the Russian Federation - the Republic of Tatarstan.

The detection of uneven spatial distribution of labor force is of particular relevance to the regional management. Spatial heterogeneity is one of the key tasks in the economic geography. The problem of uneven spatial distribution of the labor force is typical for the whole Russia with its vast territory in general, as well as, for some certain regions in particular. This is the reason of imbalances at both regional and local labor markets.

\section{DISCUSSION}

Labor potential is influenced by the whole complex of social and economic conditions. E.A. Saprykin [5] identified two approaches to the definition of the labor potential. Labor potential is understood as a general characteristic of the quantity and quality of the total capacity for work of the working population on the participation in socially useful activity; labor potential is the potential of the work itself and is associated with the collective laborer. The usage of geographic approach automatically implies the analysis of the territorial system or one of its constituent elements. As a result, the potential has obviously got spatial expression. Labor potential of the territory is more complex formation compared to the employee's potential due to multiple connections. Labor potential of the territory is a system that is greater than the sum of its parts, as there are shown the related properties of the system. The latter is the result of cooperative effects in the implementation of certain activities of people within particular social networks. It is believed that at the level of territorial unit labor potential acquires new quality and must be designated by the term "labor force potential." From that moment it becomes the object of study of economic geography [4]. The term "labor force potential" in its narrow sense, is determined as working-age population of a territorial unit, which is involved in social production, is active on the regional labor market and can act as the subject of the labor market for various hierarchical levels. In its broader sense - it is not only the potential the society has today, but also the one that could be in the perspective. Finally, in the broadest sense it is the system comprising both proper labor force potential and social geographic environment in general [3].

In the analysis of labor force potential of the territory it is necessary to quantify the scope of the object being analyzed, as well as, to define the sufficient components of the analysis. In the quantitative analysis, the closest meaning of the concept " labor force potential" is the term - "economically active population ". This category includes all economically - active population, as well as, those who may become economically active in changing socio-economic situation. If we take the factorial approach as a basis to analyze labor force potential, it automatically goes beyond the qualitative and quantitative analysis of the workforce. The assessment of factor component, in its turn, will have a relative nature and be calculated with the use of subjective methods of assessment [3].

\section{METHOD}

The study of theoretical data allowed the authors to provide an assessment of labor force potential of the Republic of Tatarstan. The main factors reflecting the status of labor force potential are the following: the proportion of the labor force in the total population; the share of the working age population in the total population; the share of employed in the total labor force; the share of employed in the total labor force (in the main branches of the economy); unemployment rate. Selected parameters of the model are the most significant and can have quantitative analysis.

To understand the features of the spatial heterogeneity of the distribution of labor force potential on the territory of the Republic of Tatarstan, we studied all administrative districts of the republic ( at the time of the study there were 43 districts).

\section{FINDINGS}

Currently, the number of labor force in the Republic of Tatarstan accounts 2.4 million people. Labor force potential of the Republic of Tatarstan is formed from the working age population (94\%), adolescents and working pensioners $(5.2 \%)$, foreign migrant workers $(0,4 \%)$. The total number of 
labor force of the republic is composed as follows (see Table $1)$.

TABLE I. THE STRUCTURE OF LABOR FORCE DYNAMICS OF THE REPUBLIC OF TATARSTAN $(\%)$

\begin{tabular}{|l|l|l|l|l|l|}
\hline & $\mathbf{2 0 0 7}$ & $\mathbf{2 0 0 8}$ & $\mathbf{2 0 0 9}$ & $\mathbf{2 0 1 0}$ & $\mathbf{2 0 1 1}$ \\
\hline total labor force & 100,0 & 100,0 & 100,0 & 100,0 & 100,0 \\
\hline $\begin{array}{l}\text { population in active } \\
\text { working age }\end{array}$ & 96,1 & 95,9 & 95,8 & 95,3 & 94,8 \\
\hline adolescents & 0,1 & 0,1 & 0,1 & 0,1 & 0,1 \\
\hline working pensioners & 3,8 & 4,0 & 4,1 & 4,6 & 5,1 \\
\hline
\end{tabular}

The share of able-bodied population in the total labor force is decreasing, despite the increase in the absolute amount of working age population over the last ten years. This decline equals $1.3 \%$. There was an increase of $1.3 \%$ in the number of the category "working pensioners and adolescents". The proportion of working pensioners grew from $3.8 \%$ in 2007 to $5.1 \%$ in 2011 . This can be explained by the fact that the amount of pensions does not correspond to the minimum subsistence level, which naturally leads to the fact that pensioners continue working. There was no sufficient change in the proportion of adolescents $(0.1 \%)$.

Younger generation does not tend to work on the job specialties, which have currently lost their prestige. All these resulted in labor shortage in this sector. The problem can be solved by increasing the additional workforce. It can be achieved by attracting it from other regions, including near and far abroad countries. This measure can make a difference not only in the quantitative description of the working population, but also in its qualitative characteristics. Also, in recent years there are debates about increasing the working age.

To solve the problem of comparing the factors which are used to estimate labor force potential of the region, the authors offer to implement an empirical approach. The latter is based on index method of combining indicators of diverse quantities. The proposed method provides a non-verbal, descriptive and comparative description of the state of labor force potential of the region. It allows one to get a well-defined, quantitative and objective characteristic which encompasses the whole set of considered indicators.

The method used in the study involves the removal of points estimating the quantities of each of the factors that characterizes the labor force potential of the territory. To get the points, we need to draw a scale of ranges of real quantities for each of the factors for all districts of the republic. The ranges are determined on the basis of minimum and maximum quantities of this factor. Further, the ranges are divided into ten equal intervals, where each interval corresponds to a certain number of points. Thus, the sum of all points of the chosen factors characterizes the integrated assessment of labor force potential ( ILFP) of the territory and can be represented by the formula:
$I L F P=\sum_{i=1}^{N} P_{i}$

where " $\mathrm{i}$ " is a factor; $\mathrm{N}$ - a number of factors; $\mathrm{Pi}$ - point that corresponds to the quantity of the $\mathrm{i}$-th factor.

According to the results of the assessment of labor force potential of the Republic of Tatarstan, we divided all administrative districts into 5 groups (Figure 2): 1. The districts which are characterized by a high level of labor force potential. This group includes Tukaevsky, Nizhnekamsky districts, as well as, the city of Kazan and Naberezhnye Chelny; 2 . The districts which are characterized by an above average level of labor force potential. This group includes Aznakaevsky, Bugulminsky, Buinsky, Zainsky, Pestrechinsky, Rybno-Slobodskiy, Sarmanovsky, Almetyevsky and Yelabuzhskiy districts; 3 . The districts which are characterized by an average level of labor force potential. This group includes: Agryzsky, Alexeevsky, Baltasinsky, Vysokogorsky, Mendeleevsky, Nurlatsky, Bavlinsky, Zelenodolsky districts; 4. The districts which are characterized by a below average level of labor force potential. This group includes: Aksubaevsky, Apastovsky, Atninsky, Leninogorsky, Menzelinsky, Muslyumovsky, Sabinsky, Spassky, Cheremshansky, Chistopolsky, Yutazinsky, Aktanyshsky, Kama-Ustyinsky, Tetyushsky, Arsky, Tyulyachinsky, Kukmorsky, Novosheshminsky, Alkeyevsky, Kaybitsky, Drozhzhanovsky, Laishevsky, Verkhneuslonsky districts; 5. The areas characterized by a low level of labor force potential. This group includes Mamadyshsky district.

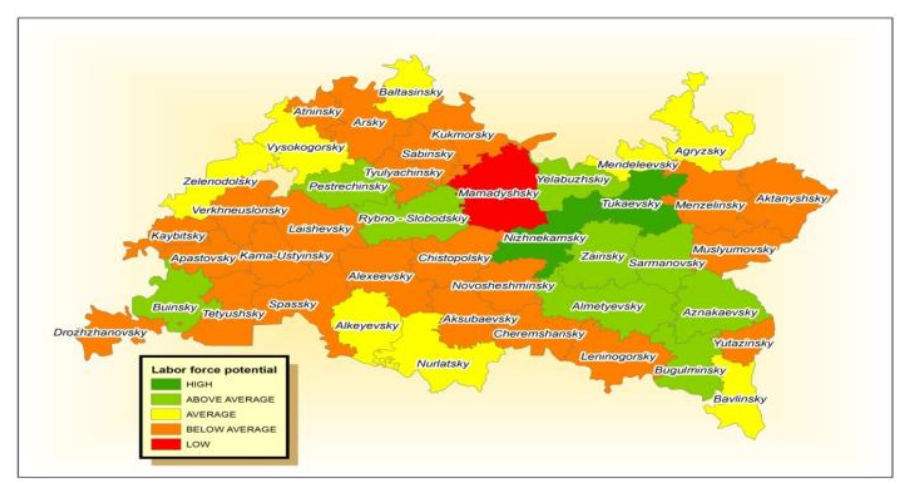

Fig. 2. The assessment of the Republic of Tatarstan's labor force potential

The obtained results demonstrate the predominance of districts with below average and low levels of labor force potential.

The integral characteristic of labor force potential in these districts have low quantities. It allows us to conclude that there are depressive processes on the respective labor markets. So, at the beginning of 2014 the registered unemployment rate in the republic amounted to $0.89 \%$. In 15 districts the rate of unemployment is below the average republican level that undoubtedly creates a threat to their economic security. High unemployment rate is registered in Tetyushsky (2.02 \%), Chistopolsky $(1.90 \%)$ and Sabinsky $(1.81 \%)$ districts. The 
map indicates the locations of studied municipal districts in the central and south-eastern parts of the Republic of Tatarstan with the centers in the largest cities with population over 100 thousand people. Those places are said to have relatively high levels of labor force. The first center is in Kazan and the surrounding areas. $38 \%$ of the total number of people employed in the national economy are concentrated here. It is also the place that contributes $28 \%$ to gross regional product (GRP). The second largest center is the Kama economic region with the industrialized cities of Naberezhnye Chelny, Nizhnekamsk, Zainsk and surrounding areas. It should be noted that Nizhnekamsk is the place with highest concentration of labor force. Its territory includes $26 \%$ of total population employed in the sectors of economy and it produces $23 \%$ of GRP. An above average level of labor force potential is observed in Almetyevsky, Sarmanovsky, Bugulminsky, Aznakaevsky districts. The districts provide one-eighth of the total labor force of Tatarstan and produce 30 $\%$ of GRP.

The discussed centers play a significant role in the internal and external social and economic processes of the Republic of Tatarstan. They have a diversified industry, are involved in the intra-division of labor, producing the products, which target both domestic and foreign markets.

The remaining districts located in south-western, northeastern parts of the republic have below average level of labor force potential, and contributions to the economy of the republic accordingly. These areas are predominantly agricultural and characterized by low quantities of labor force potential. So, $4 \%$ of the economically active population of the republic live in Apastovsky, Drozhzhanovsky, Kaybitskom, Kama-Ustyinsky, Tetyushsky districts. Only $2 \%$ of Tatarstan's GRP is produced here. In the districts of the republic like Atninsky, Arsky, Sabinsky, Tyulyachinsky, Kukmorsky and Mamadyshsky the amount of labor force does not exceed $6.2 \%$ of the total employment of able-bodied citizens. Contribution to GRP is also not great and accounts for $2.6 \%$.

The number of employed in the economy in the districts as Spassky, Alkeyevsky, Chistopolsky, Novosheshminsky, Aksubaevsky, Cheremshansky, Leninogorsky is comparable to the northern areas of the republic. However, the contribution to the GRP, due to oil-producing, instrument-making enterprises, as well as, light and food industries, is twice higher and reaches $5 \%$ (of total republican rate). Eastern administrative districts - Menzelinsky, Aktanyshsky, Muslyumovsky, Yutazinsky - with the share of the employed population of $6.4 \%$ (of the total population of the republic), contribute $9 \%$ to the GRP.

Thus, the predominance of reduced and low levels of labor force potential occurs in areas with low quantities of the characteristics of the socio-economic development in general. If stagnation processes continue, they may lead to the increase of dissonance in the spheres of economic growth at intraregional and interregional levels.

\section{CONCLUSION}

To prevent territorial heterogeneity of labor force potential, it is proposed to create some new industrial centers in lagging districts that would certainly strengthen and enhance local capacity. When human resources of the territory are used in full, they allow to produce maximum gross product. Recently, we have got positive changes in demographic policy. It happened due to the measures like: supporting families with children; introduction of health security programs. However, due to the unfavorable structure and because of the aging of population in general it is expected the shortage of able-bodied citizens. The situation could be explained by the fact that the generation that is supposed to represent new labor force was born in the early 90-s - the period of lowest level of birth rate from the postwar period. The reduction of working-age population would result in serious problems in the economy.

To achieve the goal of economic growth is impossible without an increase in the quality of work. Taking into account the demographic decline, the effective use of labor force in the short term would be the only possible factor in the growth of GDP. Understanding the status and trends of the dynamics of labor force potential of the Republic of Tatarstan would allow the region to build a competent management of the key factors for future economic development [2].

\section{REFERENCES}

[1] V.A. Borisov, Demography: Textbook, Moscow, 2005

[2] E.J. Isayev, V.A. Rubtsov, N.K. Gabdrakhmanov, The main directions of the dynamics of labor resource potential of the Republic of Tatarstan, News of Smolensk State University, 2014, № 4 ( 28 ), pp. 262-274

[3] A.A. Litvinov, V.A. Rubtsov, N.K. Gabdrakhmanov, E.J. Isayev, G.R. Ahunzyanova, G.N. Bulatova, Zoning territories of the Republic of Tatarstan and Udmurtia in the level of demographic potential, Bulletin of Udmurt University, 2013, № 6-3, pp. 123-130.

[4] V.A. Rubtsov, N.K. Gabdrakhmanov, E.Y. Isaev, The demographic and labor resource potential of the territory: role, place, approaches. Concepts and definitions, Environmental Consulting (natural resources, territorial development ), 2012, No. 3 (47), pp. 2-14.

[5] E.A. Saprykin, The economic content of the category "employmen potential of the region ", Economic labor in Russia, Saratov: Saratov State Technical University, 2001.

[6] V.A. Rubtzov, N.K. Gabdrakhmanov, M.R. Mustafin, O.V. Pratchenko, Methodological issues of monetary valuation of natural resources, International Business Management, no. 10(21), 2016, pp. 5089-5092.

[7] V.A. Rubtzov, N.K. Gabdrakhmanov, O.A. Delabarr, D.V. Tyabina, Equilibrium tasks in geography, Mediterranean Journal of Social Sciences, no. 6 (3), pp. 669-672.

[8] V.A. Rubtsov, N.K. Gabdrakhmanov, M.R. Mustafin, N.V. Arzhantseva Optimization model of making a decision in the conditions of uncertainty (correlation of interests and preferences in regional systems), Mediterranean Journal of Social Sciences, no. 6 (3), pp. 781-785.

[9] V.A. Rubtsov, N.K. Gabdrakhmanov, M.R. Mustafin, N.V. Arzhantseva, A.M. Trofimov, Field theory in geography and stable structure of geoformations, Mediterranean Journal of Social Sciences, no. 6 (3), pp. 673-676.

[10] N. Biktimirov, N.K. Gabdrakhmanov, V. Rubtsov, M. Mustaphin, N. Arzhantseva, Peculiar features of the tatar people migration on the territory of Tatarstan, Mediterranean Journal of Social Sciences, no. 5 (24), pp. 267-271

[11] V.A. Rubtzov, N.K. Gabdrakhmanov, M.R. Mustafin, O.V. Pratchenko, Geodemographic potential of the republic of tatarstan: Analysis, evaluation, territorial differences, Mediterranean Journal of Social Sciences, no. 5 (24), pp. 278-284. 